\title{
Rethinking Financial Inclusion: From Access to Autonomy
}

\author{
Srihari Hulikal Muralidhar ${ }^{1}$, Claus Bossen ${ }^{1} \&$ Jacki O’Neill $^{2}$ \\ ${ }^{1}$ Aarhus University, Denmark; ${ }^{2}$ Microsoft Research India, Bangalore \\ 1(srihari; clausbossen)@cc.au.dk; ${ }^{2}$ jacki.oneill@microsoft.com
}

\begin{abstract}
Financial inclusion has been defined and understood primarily in terms of access, thereby constituting 'inclusion'/'exclusion' as a binary. This paper argues such a view to be myopic that risks treating financial inclusion as an end in itself, and not as means to a larger end. 'Access' oriented perspectives also fail to take into account considerations of structural factors like power asymmetries and pay inadequate attention to user practices. Through the case of auto-rickshaw drivers in Bangalore, India, and their use of Ola, a peerto-peer taxi hailing service similar to Uber, we show that access is a necessary, but not sufficient condition to achieve financial inclusion in a substantive sense. By examining in detail, the financial needs and practices of rickshaw drivers, we identify the opportunities and constraints for digital technology to better support their financial practices and enhance their wellbeing. The paper proposes adding 'autonomy' and 'affordances' as two crucial factors to be included in the discourse on financial inclusion. Finally, we outline design implications for P2P technologies to contribute towards the financial inclusion of drivers.
\end{abstract}

\section{Introduction}

Financial inclusion is defined as a process of 'ensuring access to appropriate financial products and services [.... at an affordable cost, in a fair and transparent manner, by regulated, mainstream institutional players' (Singh and Reddy, 2018). Financial inclusion has also been defined sometimes in terms of what it is not i.e. through exclusion, rather than what it is (Roy, 2010; Musaraj and Small, 2018). Certain marginalized groups, across contexts, do not enjoy access to formal financial services such as bank accounts, savings and insurance products, payments services, and so on. This exclusion, in turn, has shaped financial inclusion in terms of providing access as a concept and as policy agenda. Ensuring access to financial products and services to all, particularly the vulnerable sections of society, at reasonable costs, has emerged as an integral component of development apparatus of developing countries across the globe.

Following Jeffrey Sachs's call for an 'end of poverty' (2005), new development programs and strategies have been formulated towards achieving poverty alleviation, one of which is harnessing technology. This includes an emphasis on digitization of money across sectors, from cash transfers to mobile money (Musaraj and Small, 2018). These developments have led international organisations, governments and philanthropic organisations to embrace digital money and platforms in order to leverage them for the benefit of low-income, marginalized communities. The Gates Foundation, for example, has argued that 'because most 
poor households conduct most or all of their financial transactions in cash [it] perpetuates the poor's marginalization from the formal economy...' (Gates Foundation, 2012). Such campaigns perceive the dematerialization of money i.e. a shift from cash to digital payments as 'a technological fix to broader problems of poverty and financial exclusion' (Musaraj and Small, 2018, p. 7).

In some instances, having a mobile phone does provide access to expedited monetary transactions and enables sending remittances across long distances at low costs, and thus acts as a lever for financial inclusion (Mas and Morawczynski, 2009). In other instances, however, it does not make much of a difference, or worse, can have a detrimental impact (Papaioannou, 2011; Kiiti and Mutinda, 2018; Donovan, 2018). Mobile money's largest success stories have been of M-PESA in Kenya (Mas and Radcliffe, 2011; Kendall et al., 2012) and GCash in the Philippines (Gusto and Roque, 2018). These successes have not been replicated in other settings, since they rely upon broader social and cultural factors like large inflows of remittances, favourable regulations, and so on. Overall, experiences with leveraging digital money for financial inclusion are mixed (Nelms and Rea, 2017; Maurer et al., 2018). There is a need for greater attention towards the financial practices of low-income communities and the broader ecosystem around financial transactions.

It is in the context that we present our case of auto rickshaw drivers in India. Here, the government, like many other governments in the developing world, has been pushing a financial inclusion drive by opening bank accounts for the unbanked, resulting in 307 million new accounts opened under the Prime Minister's Financial Inclusion Mission, as of December 2017 (Singh and Reddy, 2018). Also, as part of the 'Digital India' vision', the Indian Government in 2016 banned high denomination currency notes to promote cashless transactions, to curb the menace of black money, corruption, and terror funding (Jaitley, 2017). However, India's tryst with mobile money to act as a lever of financial inclusion has so far met with limited success (Medhi et al., 2009; Morawczynski et al., 2010; O'Neill, Dhareshwar, and Muralidhar, 2017; Nandhi, 2018). In this paper, we analyse autorickshaw drivers' experiences using a peer-to-peer (P2P) taxi-hailing platform Ola, which was launched in Bangalore in 2014. Ola, like Uber, connects commuters with drivers through a smartphone application, and has a mobile wallet called Ola Money embedded as part of its app.

Our contribution is three-fold. Firstly, and most importantly, by examining rickshaw drivers' use of Ola Money, alongside prior research into the use of bank accounts (Morawczynski et al., 2010) and digital money (Blumenstock et al., 2015; O'Neill, Dhareshwar and Muralidhar, 2017), we pose a challenge to the current definition of financial inclusion as being about access to affordable formal financial services. We call for a broader understanding of financial inclusion, as being about increasing the financial wellbeing of low-income communities. We believe this broader framework better captures the intent, goal or end of financial inclusion which gets lost in translation when we focus only on access. Secondly, we build on research in human-computer interaction $(\mathrm{HCI})$ and $\mathrm{CSCW}$, primarily conducted in

\footnotetext{
${ }^{1} \mathrm{http} / / /$ digitalindia.gov.in/content/about-programme
} 
the Global North which examines the different forms that money takes and specifically how digitisation impacts on its social meanings and the situated practices surrounding its use (for example, Pritchard, Vines, and Olivier, 2015; Mainwaring, March, and Maurer, 2008; Hughes and Lonie, 2007; Kumar, Martin and O'Neill, 2011; Vines, Dunphy, and Monk, 2014; Ferreira, Perry, and Subramanian, 2015). This paper extends this literature, by illustrating how marginalized communities can be excluded from the supposed benefits of digitization by the very design of digital money, if care is not taken to include them as active participants rather than passive recipients. Ironically, any benefits accrued from digital payments by the drivers were incidental coming from their position on the periphery of the digital money ecosystem. That drivers were not fully included in this ecosystem, able only to exchange digital money for cash by design, is part of a larger phenomenon, familiar to the HCI community: that of gig economy platform design which tends to prioritize customer needs over workers' (Gloss et al., 2016; Rosenblat and Stark, 2016; Ahmed et al., 2016; Martin et al., 2016). This brings us to our third contribution, which is illustrating how this holds true in not just the way payments are given or withheld (Bederson and Quinn, 2011; Felsteiner, 2011; Silberman, 2010; Silberman, Irani, and Ross, 2010; Morozov, 2014; Isaac, 2014), but in the dynamics of how payments are handled through the technology.

The paper is structured in the following way: Section 2 presents the related work and highlights the key takeaways for the present case. Section 3 describes the setting and methodology. Section 4 presents the findings from the case study. Section 5 discusses the empirical findings in relation to the larger discussions around digital money and financial inclusion, including design implications; and finally Section 6 concludes with perspectives on conceptual broadening of financial inclusion, and design of digital money and platforms to support financial inclusion.

\section{RELATED WORK}

We present the central issues and the relevant literature in four subsections, organized thematically as follows: monetary practices, financial inclusion, digital financial services, and the emergence of gig work platforms.

\subsection{Monetary Practices and Cash}

Money, irrespective of its form, is not merely a medium of economic exchange or a legal tender. It is an artefact embedded in social and cultural practices, and therefore, imbued with meanings and uses that are constantly under negotiation (Zelizer, 1995). 'The study of money and its exchange is therefore necessarily a study of how meaning and value are assigned by those who use it' (Perry and Ferreira, 2018). Meanings and values associated with money become apparent when we examine practices around money. Regarding different forms of money, tangibility, immediacy, and universal acceptance are some of the most important affordances of cash. For example, cash, like a bearer cheque or bond, belongs to 
the person physically possessing it. On the other hand, it always carries with it the risk of theft or loss. In the case of low-income, marginalized communities, lack of access to bank accounts, cards or Internet have contributed to basic financial practices and institutional arrangements predominantly around cash ${ }^{2}$. Smartphone ownership along with Internet access is still largely restricted to the more affluent classes.

At the same time, issues around trust, safety, and the presence of supportive social infrastructures have to be considered in discussing cash versus other forms of money (Kumar et al., 2011; Vines, Dunphy, and Monk, 2014; Ferreira and Perry, 2014; O'Neill, Dhareshwar, and Muralidhar, 2017; Nandhi, 2018). In the case of low-income people in the UK, Vines, Dunphy, and Monk (2014) identify privacy concerns as being an obstacle to using digital technologies like internet banking to manage finances. This holds for the developing world too, as illustrated by the findings reported from Ghana (Yu and Ibtasam, 2018) and India (Pal et al., 2018). In cases like Kenya, which is considered a huge success in mobile money uptake, it is the presence of a mix of social, economic, and cultural conditions that have contributed to its massive use (Mas and Morawczynski, 2009; Kendall et al., 2012). The success cannot be attributed to technology alone. In Ghana, users reported that they did not want others (neighbours, friends, relatives etc.) to know that they had money with them, as it would lead to a social pressure to lend and this, in turn, resulted in sporadic activity with their bank accounts (Yu and Ibtasam, 2018). Similarly, small shop owners and vendors in India had concerns about cashless transactions enabling government surveillance on their financial lives, particularly in relation to taxes (Pal et al., 2018). Social and cultural concerns, preferences and practices are crucial for whether, when and where people use cash or go for cashless transactions.

In relation to the financial practices of low-income groups, previous studies have highlighted a number of interesting characteristics relevant for our analysis. Low income groups, in contrast to the more privileged sections of society, 'borrow in order to save': saving up often requires extended effort over a long period of time, and in this period, people rely on small (sometimes interest-free) borrowings from family and friends to meet certain exigencies (Rutherford, 2009; Collins et al., 2009; Banerjee and Duflo, 2011). This might seem counterintuitive, but the reason they do this is that it is much harder for low-income households to accumulate savings than repay the interest-free loans they can access by leveraging their social and cultural ties. Credit, both short- and long-term, then, is inextricably interrelated to savings practices, not just managing expenses. Furthermore, low-income groups in both developed and developing regions categorize money to different chunks intended for specific expenses (Zelizer, 1995; Collins et al., 2009; Vines, Dunphy, and Monk, 2014). In other words, they engage in 'ear-marking' money for specific purposes (such as school fees and loan payment). Both borrowing and savings practices, as well as managing cash flows for both short- and longer-term needs,

\footnotetext{
2 This is because economic exchange in the informal sector takes place mostly through cash. Wages are paid in cash. Exchange of goods and services are also done in cash. Lending, saving etc. are mostly done in cash (and sometimes kind - gold, land, cattle/goats etc.).
} 
may be done through formal (bank accounts) as well as informal channels (savings clubs, cash at home, gold etc.).

\subsection{Household Coordination of Money}

Previous research in CSCW and HCI that has looked at household management of finances has stressed at the importance of financial practices that have evolved organically and the use and non-use of technology in this context (Kaye et al., 2014; Vyas et al., 2016; Halloluwa et al., 2018; Lewis and Perry, 2019). Kaye et al. (2014)'s study showed that digital tools for money management were not used by households in the US, despite having access to them, due to concerns around safety of transactions, mismatch of user needs and tool design, and the additional work that made it inconvenient. In a similar vein, from their ethnographic study of fifteen families in Australia, Vyas et al. (2016) found that whilst on the one hand, families had access to internet banking and used it, on the other hand, they mostly used physical tools such as envelopes and calendars for household coordination of finances. They note that it is important to be critical about whether a technology is a solution at all in these contexts. In a more recent study, Lewis and Perry (2019) examined the practices around tracking of personal finances - why it is done, when, by whom, and most importantly how. They report that users put in extra work in order to track information within and across the physical and digital artefacts they used for financial management. Their findings challenge the notion that the shift from cash to cashless results in easier and flexible management of money, echoing previous studies (O’Neill, Dhareshwar, and Muralidhar, 2017; Perry and Ferreira, 2018). Furthermore, structural factors such as power asymmetries within the household along gendered lines and the values associated with money by different household members become important when designing technologies for financial management. Halloluwa et al. (2018), for instance, in their study of everyday financial practices amongst low-income, underbanked women in rural Sri Lanka, found that independence and a desire to support their families were priorities for their participants, and underpinned their financial decisions and activities.

\subsection{Financial Inclusion}

Across the globe, low-income groups experience small, irregular, and unpredictable incomes, adding uncertainty to the fundamental challenges of not having sufficient money (Collins et al., 2009; Banerjee and Duflo, 2011). Low income households are further vexed by the poor quality of financial products and services available to them. Collins et al. (2009), in their seminal, longitudinal study of household financial management by those living at an average daily income of $\$ 2$ or less, provide three important criteria by which the financial instruments can be assessed: Reliability, Convenience, and Flexibility. Reliability can be understood as an umbrella term encapsulating transparency and security of the financial instruments. Convenience refers to their accessibility and affordability. 
Flexibility is an important criterion, as the poor do not have secure jobs with regular, stable incomes. They further identify three main financial needs of lowincome communities for which support is often inadequately provided: help with managing day-to-day finances; help with accumulation of savings in the mid- to long-term; and help with gaining access to credit and insurance. These points have been highlighted by others as well (Rutherford, 2009; Banerjee and Duflo, 2011).

It is against this context that the financial inclusion agenda and the hopes pinned on digital money needs to be analysed, since access to bank accounts and other financial services is thought to provide reliable, convenient and flexible ways to manage their money, help accumulate savings and obtain access to credit. Thus, 'financial inclusion' has emerged as an integral component of the development apparatus across contexts. Financial inclusion is claimed to help the poor 'weather inflation and price volatility' (Economic Survey, 2015, p. 53), and 'enable government to support them, provide cushion for financial vagaries, and help them achieve their economic aspirations' (Economic Survey, 2016, p. 64). Given the claims made around benefits to be derived from financial inclusion, it is important that there exists enough clarity on what is meant by 'financial inclusion' in the first place. Whilst there is no universally agreed-upon definition, a review of existing literature indicates that they all share a common focus on access. For instance, financial inclusion has been defined as 'the process of ensuring access to timely and adequate credit where needed by vulnerable groups such as weaker sections and low income groups at an affordable cost' (Rangarajan Committeee, 2006) ${ }^{3}$. Terming the primary focus on expansion of credit as 'putting the cart before the horse', another definition has been put forth that includes other financial services such as payments, savings, insurance and so on (Raghuram Rajan Committee, $2008)^{4}$. Financial inclusion, thus understood primarily in terms of 'access to formal financial services', is argued to allow individuals the 'opportunity to plan, save, and stabilize their financial lives' (Yu and Ibtasam, 2018, p. 1).

However, whilst the notion of 'financial inclusion' focuses on 'access', a distinction needs to be made between 'access' to financial products and services, and 'usage', that is, the ways customers use the services available (Koh et al., 2017). This distinction is crucial because 'access' does not automatically translate into 'usage', as previous studies have shown (Morawczynski et al., 2010; O'Neill, Dhareshwar, and Muralidhar, 2017). In the Indian context, for example, the government's 'mass-banking initiative' has resulted in opening of bank accounts at scale, but a majority of them are never used or underused, 'remaining merely symbols of financial inclusion rather than practical tools' (Nelms and Rea, 2017, p. 19). A quantitative study in India based on household-level survey data similarly points to the importance of this distinction (Ghosh, 2017). Thus, while access to a bank account might serve as a useful starting point, it does not imply usage, and the question remains as to what factors shape and promote usage, and what can done to better support user-practices? Additional questions include what kind of activity

\footnotetext{
3 http://pib.nic.in/newsite/erelease.aspx?relid=35141

4 http://planningcommission.nic.in/reports/genrep/rep_fr/cfsr_all.pdf
} 
low-income groups are performing with their bank accounts and how often? How well do financial products and services fit their needs?

Some previous studies have already recommended expanding the definition of financial inclusion to include other relevant factors. For instance, Saurabh (2017) argues that the discourse on financial inclusion must address the ' 5 A's': availability, accessibility, acceptability, affordability, and awareness (p. 37). Client protection, robust financial infrastructure, and clear regulatory framework have been included as well (The Centre for Financial Inclusion, 2016). However, none of these definitions or frameworks direct our attention to the ends that make financial inclusion important. They simply point to some of the means that, inter alia, play a prominent role in the process ${ }^{5}$. In this paper, we make an argument for concentrating on the overarching objective of financial inclusion, namely enhancing financial autonomy and capabilities of low-income, marginalized groups. The particular means or instruments through which it can be achieved is of secondary importance.

\subsection{Digital Financial Services}

Financial service delivery is argued to be shaped by two main factors: sustainability for the service providers and affordability for the customers (Sun, 2017). Mainstream banking systems have failed in delivering financial services to the poor mainly because of the former, since it is too expensive for banks to provide set up brick-and-mortar branches, given the low levels of activity involved (by volume as well as value) (Morawczynski et al., 2010; Mas and Radcliffe, 2011; Chu, 2017; Nandhi, 2018). Formal financial services being unaffordable has also been one of the factors found that resulted in limited uptake and activity with bank accounts (Medhi et al., 2009). The Government of India has identified three steps in the process of promoting financial inclusion: First, the government must be able to identify the beneficiaries; second, they must be able to transfer social security payments and benefits to them; and third, and perhaps most importantly, the beneficiaries must be able to easily access such benefits (Economic Survey, p. 51) ${ }^{6}$. This latter step, also termed the 'last-mile connectivity problem' of getting money from banks into people's hands (and vice-versa) has posed the biggest constraint in achieving financial inclusion in a substantive way. Given that more than 90 percent of the Indian workforce operates in the unorganized sector (often on a daily wage basis), physically accessing banks entail huge costs (transactional costs, travel costs, and opportunity costs in terms of daily earnings lost) (Morawczynski et al., 2010; O’Neill, Dhareshwar, and Muralidhar, 2017). It is this last-mile connectivity

5 Amartya Sen (1999) makes a similar argument about development, critiquing narrower perspectives of development in terms of equating it with GDP, industrialization, modernization and so on. Development, he argues, is a "process of expanding human freedoms" (p. 3).

6 Freund (2017), in his paper on using blockchain for achieving financial inclusion on a global scale, argues that 'financial inclusion starts with identity; everything else is derived from it' (p. 438). A trusted legal digital identity, which is facilitated by blockchain technology, will obviate the need for a bank account. 'Anybody, anywhere in the world can participate as long as they have internet access through a smartphone' (p. 443). 
problem where digital technology is supposed to help the most, since digital money transfer via mobile phones would save travel expenses and lost earnings (Saurabh, 2017).

Besides lowering transaction costs, an additional benefit that digital technologies offer is that digital transactions leave an electronic trail behind them, which previous studies have noted to be important for low-income groups in terms of not only creating transparency ${ }^{7}$, but also establishing a financial history (See Saurabh (2017) and Muralidhar et al. (2018) for more). For example, Ant Financial, an Alibaba subsidiary, manages AliPay in China that allows both users and businesses to build an identity and financial history (Chu, 2017). Thus, an argument is made that mobile inclusion and financial inclusion go hand-in-hand because they are driven by the same key factors, namely: accessibility, affordability, and availability of an open ecosystem (ibid, p. 133).

However, digital financial transactions are not without disadvantages or limitations. For low-income groups in developing parts of the world, where transactions have almost exclusively been based on cash (or cash and kind), cashless transactions are not always practical, because of a lack of access to pointof-sale (PoS) terminals (Sahoo and Arora, 2017; O'Neill, Dhareshwar, and Muralidhar, 2017). India, for example, not only has one of the lowest penetration of PoS terminals for cashless transactions in the world (Mukherjee and Goyal, 2017), but banks also levy charges in case of card payments (ibid). Therefore, it is hardly surprising that people prefer transactions by cash and that $92 \%$ of card transactions were cash withdrawals from ATMs (Saurabh, 2017). Similar findings have been reported from other parts of the developing world as well. Digitization of salary payments in Afghanistan, for instance, was found to deliver immediate benefits in terms of cost savings to the employer organization, whereas the impact on recipients' financial well-being was found to be negligible (Blumenstock et al., 2015).

Koh et al. (2017) model the journey of building the infrastructures and providing the services for an inclusive digital economy as a four-stage, evolutionary process. In the first stage, the main objective is to provide mobile and internet connectivity to the people. In the second stage, building on the basic infrastructure provided in stage one, the goal is to create a basic payments system for the unbanked. In the third stage, the goal is to provide people with a full range of digital financial services such as savings, micro-credit, insurance, and so on. The main challenge at this stage is interoperability between the financial sector's networks and the transactional system developed by the telecom networks. The fourth and final stage is an inclusive digital economy where the currently unbanked have access not only to a full suite of financial services but are also able to carry out most of their purchases and other transactions digitally. Building on this framework, we identify in this paper the key possibilities and challenges in moving from one stage onto the next in a given context by taking a bottom-up, practice-centred approach.

7 Of course, how accessible and beneficial such a trail is, in reality, for people with limited access to technology and minimal technical literacy is a whole other question, and one of the reasons why paper receipts remain popular in low resource settings (Panjwani et al., 2013; Ghosh et al., 2015; O'Neill, Dhareshwar, and Muralidhar, 2017) 


\subsection{Gig Work Platforms}

The emergence of gig work platforms, and the optimism generated that they can help to improve outcomes for all the actors involved, in some ways parallels the interest in harnessing technology for development purposes. "Platform' has been deployed in both populist appeals and marketing pitches... as platforms of opportunity...' (Gillespie, 2010, p. 1). However, that optimism has largely remained unfulfilled. From Uber to Amazon Mechanical Turk, studies have shown that technology mediating the relations and practices in the workplace does not improve conditions for workers (Gupta et al., 2014; Lee et al., 2015; Irani, 2015; Martin et al., 2016; Glöss et al., 2016; Ahmed et al., 2016; Shapiro, 2017). Indeed, in the case of Amazon Mechanical Turk, workers were low-paid and received little recognition whereas their managers were heralded as innovators and entrepreneurs (Irani, 2015). Service providers (a.k.a. the workers) using P2P platforms to connect to customers are often anxious bordering suspicious about the algorithms mediating those connections because of a lack of adequate understanding of how they work and a lack of control (Rosenblat and Stark, 2016; Martin et al., 2016; Glöss et al., 2016; Ahmed et al., 2016). Such 'algorithmic anxiety' results in them having to engage in 'double negotiation' with the customers as well as the platform (Jhaver et al., 2018).

Furthermore, these technologies are not just a new kind of marketplace that matches supply and demand. They mediate labour relations as well (Raval and Dourish, 2016; Shapiro, 2017). Consequently, new forms of material and immaterial labour are performed by different stakeholders. 'Rating system', for example, where customers rate the service providers, necessitates that 'emotional labour' is performed by the service providers so that they are rated positively and do not suffer in the future (Raval and Dourish, 2016; Harmon and Silberman, 2017). Even with digital technologies that enable cashless transactions, which are promoted for their 'anytime, anywhere' convenience, research indicates that there is considerable labour involved in their maintenance and use that often remains invisible (Pritchard et al., 2015; O’Neill, Dhareshwar, and Muralidhar, 2017; Perry and Ferreira, 2018). Furthermore, in the case of the 'on-demand' taxi-hailing industry, labour relations take a new form: unlike traditional taxi companies where the drivers are considered employees, neither Uber nor Ola consider the drivers as 'employees'. Instead, they are considered 'partners', 'independent contractors' or 'micro-entrepreneurs', connected to the passengers by the platform acting as a 'digital middleman', which has implications for the drivers' rights and conditions of work (Isaac, 2014; Ahmed et al., 2016; Shapiro, 2017).

The implications of these and other related issues in the context of algorithms and work practices have already been well documented in the literature, as some of the references above illustrate. However, not much attention has been paid to how these platforms affect the financial practices of low-income groups, and the related problems and possibilities in the context. For instance, payments made by customers are routed through the platform (Uber, Ola, Airbnb etc.), which assumes a central place in this ecosystem. What are the implications of such a design? What are the benefits and disadvantages and for whom? Similarly, while P2P platforms 
mediate relations between service providers and customers and hence the access to a larger pool of potential customers (for providers) and choice of providers (for customers), these platforms have also been shown to change work conditions and introduce new layers of uncertainty and opacity for both service providers and customers. Toyama (2015), in discussing the role of technology in social change more generally, formulates that technology acts as an amplifier of human intent and ability. What is relevant for our discussion is amplification of whose ability and whose intent, how, and at what cost. These questions will be considered in our analysis as they shed light on the consequences for the well-being of both drivers and customers.

\section{Methods and Setting}

Ethnographic fieldwork has proven extremely valuable in $\mathrm{HCI}$ and CSCW research, since participant-observation and interviews are effective ways of eliciting the interconnectedness of actors, technologies and practices (Randall, Harper, and Rouncefield, 2007). This paper draws on the data from the observations of 12 Ola drivers, and formal, semi-structured interviews of 13 Ola drivers. Observations lasted for 6-8 hours per day and the interviews varied between 30-90 minutes. This data was collected as part of a wider ethnographic study of auto rickshaw drivers in Bangalore, India, during April-July, 2015. We used observations, in-situ interviews, and semi-structured interviews to obtain a rich picture of drivers' work and financial practices, perceptions and experiences with mobile technology. We observed 23 drivers during 14 days in the field and conducted 48 semi-structured interviews. We specifically conducted these Ola Money interviews to probe into certain recurrent themes that we had picked up from previous interviews around the use of Ola. Observations and interviews were conducted in Kannada, the official language of Karnataka state, by the first author, along with two other collaborators. The findings from the observations and in-situ interviews in relation to use of technology and work practices have already been discussed in Ahmed et al. (2016). The contribution of this paper is a focus on the financial practices of drivers and their use of Ola, specifically Ola Money, a 'mobile wallet' that facilitates cashless payments between customers and drivers.

Participants were recruited through Peace Auto, which is a collective working for auto drivers' rights. Informed, verbal consent was obtained from all participants, with separate consents for voice recording and photographs. The interview protocol covered topics ranging from demographics and auto rickshaw driving experience, to financial practices (earnings, savings, expenses, debt, use of cash, and non-cash forms of money) and use of technology. For those using Ola, the focus was on the impact of the Ola platform (including the Ola Money mobile wallet) on the drivers' work and financial practices. Data was collected through field notes, audio recordings, and photographs. The interviews were translated and transcribed into English.

For analysis, field notes and interview transcripts were documented, and read through collaboratively in order to identify themes of relevance and significance. 
Working though specific illustrations and experiences of participants' practices and use of Ola, we constructed themes around how our participants organized their financial lives, how they used the Ola app, perceptions and problems with Ola Money, and the ways they made sense of and distinguished between digital- and paper-based forms of money (and money practices). Patterns in the data were identified and labelled following the thematic process (Braun et al., 2012). Before discussing our findings, we will briefly introduce our participants and the socioeconomic and cultural context in which they operate.

\subsection{Auto-Rickshaw Drivers in India and Participant Demographics}

The auto-rickshaw sector in India, much like the taxi sectors in cities like London and San Francisco, is regulated. This has been termed as 'permit raj' (Chanchani and Rajkotia, 2012), and like the medallions that cab drivers have to obtain in case of London and San Francisco (See Glöss et al., 2016), auto-rickshaw drivers in India need a 'permit' to be able to drive. Each 'permit' is linked to a registration number. Consequently, if a driver decides to buy a new rickshaw, he will need a new permit as well. At the same time, like the medallion system, the auto driver can choose to lease his old permit to somebody else.

Auto rickshaw drivers do not fall below the official poverty line, since they have a daily income around 600-800 INR (approx. \$9-\$12) (See below). However, their financial situation is vulnerable. A vast majority of auto rickshaw permits are concentrated in the hands of a few, and are leased out at exorbitant rates, going up to 70-80,000 INR per annum (Civitas, 2010; Chanchani and Rajkotia, 2012). Even though the government is aware of this, because it is a regulated market and it wants to keep it that way, the transport authorities do not issue new permits every year, nor intervene with the concentration of permits. The implication is that more than $70 \%$ of the auto drivers do not own their rickshaws (Natarajan and Abdullah, 2014), because they lack money (or ability to repay a loan) to buy them. Instead, they typically rent auto rickshaws at a daily rate of 200-250 INR (approx. \$3 to \$4). Our participants further reported that they incurred an average of 150 INR (approx. \$2.5) for gas.

The auto-rickshaw sector, much like the cab sector, is male dominated and all the drivers in our study were male with an average age of 38.5 years, which is representative of the larger auto driver population (Chanchani and Rajkotia, 2012). All drivers in our study were multi-lingual, with varying levels of proficiency. They could all speak Kannada, the official language of Karnataka state, and understand (if not speak) at least two other languages - often English and another regional language. Almost all of them used feature phones without data. They had a mean driving experience of 13 years, and reported a daily mean income of about 600-800 INR (approx. \$9-\$12), after deducting day-to-day vehicular expenses like fuel and maintenance, with the exception of one or two who said they earned more than 1000 INR (approx. \$15). Their daily earnings typically covered their day-to-day basics, but were insufficient to enable saving up (for investments or emergencies). Eight out of 13 drivers interviewed were sole earners, and 10 of them had children going to school or college, entailing more expenses to take care of than those 
drivers who lived in their own houses and whose wives and/or children worked. These demographics, therefore, directly affected their financial situation, especially their ability to accumulate savings in the mid- to long-term. For example, when probed about savings, driver P5 made the following statement: 'Almost 95 percent of the drivers break even. They are not able to save. The remaining 5 percent who save are those with other earners in the family or live in a house of their own.' We cannot assess the exact empirical correctness of the statement, which, however, is of secondary importance: What is significant is the financial precariousness the statement illustrates, which other participants in this study and previous studies affirm. With no cushion to safeguard themselves against exigencies, and little support from the government (because they do not fall below the poverty line), auto-rickshaw drivers are financially vulnerable.

\section{Findings: Rickshaw Drivers and Digital Money}

The auto rickshaw drivers in Bangalore are an interesting case for discussing financial inclusion, digital money and gig work platforms, because, even though they are officially above the poverty line, their financial vulnerability necessitates that they constantly have to strategize: They have to generate a daily income, as they are self-employed. They are required to have a sufficient amount of money readily available for day-to-day expenses such as gas and food, while at the same time, trying to save up for exigencies and larger expenditures. While face-to-face encounters with customers and payments in the form of cash prevailed, the gig work platform Ola Auto offered new opportunities for getting customers as well as money in digital form through the Ola app.

\subsection{Drivers' Financial Practices}

In our interaction with drivers, we found that household financial management is an accomplishment between different family members, often spouses in the case of nuclear families and others (such as in-laws) in case of joint families. They collaborate to manage their precarious finances and run the household, even in families with clear divisions of labour where women were working to take care of home and children, and men were working for money. Driver P4, for example, said, 'My wife manages all our household expenses. I give her a certain amount every day and she handles the rest.' Indeed, we found three strategies for managing money, drivers managed the majority, wives (or other family members such as fathers, mothers, brothers) managed the majority, management was shared. Managing finances involved estimates of cash flows and coping strategies for emergencies and other unexpected expenses. Drivers, based on their cash flow needs, strategized and set themselves a target income at the start of their day. However, one of the characteristics of these targets is they are rather 'loose' in that drivers are well aware that they cannot always make them. As driver P1 says, 'I keep a target but some days it works out and some days it doesn't. I keep a target of 700 but some days I make around 500'. There is an element of luck to how much 
they earn and as a consequence their incomes are unpredictable. There are only so many hours a driver can work, and our participants reported already working 1215 hours per day, permitting themselves very short breaks for lunch, tea, and sometimes a smoke. Despite strategizing, drivers periodically found themselves over-stretched. As P9 says, 'Sometimes, we become over optimistic and incur more expenditure than we can handle. To handle such expenses, we sometimes take a loan. This subsequently becomes a problem.' This was due to a combination of unpredictability and low amount of income versus costs.

Saving and borrowing were both done through formal as well as informal channels. Some of them, the sole earners in particular, reported that they did not earn enough to be able to save via either channel, but still engaged in earmarking their earnings for specific needs and purposes (both short- and mid-term). Some drivers or their family members were part of informal, community savings groups and set aside a small amount every day or week towards that ${ }^{8}$. This quote from driver P2 is a good illustration:

'I pay 100 rupees to it (the savings club) every day. If I deposit 10,000 rupees, they will keep 1000 rupees for themselves and I will have 9000 rupees. When I need money for my children's school and college fees, I take money from there. If I try to do savings by myself, I will spend money for something or the other.'

Other drivers did not trust such informal channels and, therefore, saved only in the form of cash at home or in their bank account (see below). With respect to borrowing, some drivers said that they had a loan from a bank, whereas others had taken out a loan from private moneylenders. The key reason for choosing the latter was the flexibility and convenience they offered in terms of repayment schedule. To quote driver P5, 'Whenever I need some money, I do not take loan through a formal institution. I take it through private financiers. They allow us to make a daily payment. I bought this auto rickshaw on loan through a private moneylender.' Drivers also depended on their social and community ties (friends, family members, neighbours etc.) for short-term, interest-free credit. As far as savings were concerned, most drivers reported that small savings (earmarked for day-to-day basics and other short-term needs) often were held in cash at home, whereas the few drivers with relatively larger sums used a bank account or savings groups instead. As driver P11 said,

'I give my wife a certain amount every day to manage the household expenses. I do not have much savings in the bank. I might have 500 rupees or so. I save up through chits (i.e. community savings) and pay 5000 rupees towards that.'

\footnotetext{
8 These savings clubs are termed ROSCAs (rotating savings and credit associations) in development literature (Parikh et al., 2006; Collins et al., 2009; Roy, 2010; Ratan et al., 2010; Banerjee and Duflo, 2011). These have been shown to enhance women empowerment in resource-constrained settings (Maurer et al., 2018). The way ROSCAs work is that - the members pool their resources by paying small amounts monthly or weekly. The sum is then lent as micro-credit to one or more members for various expenses.
} 
What these wide arrays of practices reveal is that savings and borrowing practices constitute a broad spectrum, along which formal, transactional bank accounts (savings/loan) are only one point. Often drivers used a mix of instruments for financial management.

Although all of our participants had a personal bank account, the majority did not transact with it frequently. Unlike for the users reported in Morawczynski et al. (2010), this was due to financial constraints rather than difficulty accessing or using the account, as P6 describes, 'Procedurally, it's not difficult to carry out a transaction in a bank [...] Of course, it's a lot simpler if one has some money'. Those that did, typically made deposits and withdrawals at regular intervals, rather than accumulating much in the way of savings. Most drivers reported having between 500 INR and 1000 INR (\$7-10) in their account, with two having 6-7000 INR (\$85-100). Some merely had a nominal balance in their accounts to keep it 'active', lest the bank closes it. A couple of them had a 'loan account', which is different from a 'savings' or 'transactional account' in the Indian banking system and is used for loan repayment only. A few others had the Prime Minister Jan Dhan Account, which they called the 'Modi account' or 'zero-balance account', which had been opened in 2015 as part of the government's 'mass-banking' initiative. They found the latter beneficial for three reasons. First, the government had mandated that these accounts should not be closed on grounds that the accountholder did not maintain a certain minimum balance. Despite the lack of a minimum balance, several of drivers reported that they did have some balance (ranging from 500 INR to 1000 INR i.e. \$7-\$14). Second, they received their welfare payments to this account every month (e.g. LPG (Liquefied Petroleum Gas) subsidies in the form of cash transfers). Third, a positive externality of owning a bank account was that it provided them with a legal proof of residence.

Thus, the drivers in this study were 'under-banked' rather than 'unbanked' (See Discussion), found the zero-balance account useful, and all became engaged in a digital gig work platform that included digital money.

\subsection{Getting Rides and the Adoption \& Use of Ola}

Ola Auto was launched in November 2014, months before the Prime Minister's Jan Dhan Yojana (the mass-banking initiative) was launched. At the time of onboarding drivers, therefore, Ola opened a bank account for them and provided them with an ATM card. The system design was that the drivers' incentives and digital earnings (from customers who paid by Ola Money) would be transferred to the bank account, from which the drivers could withdraw using the ATM card. We describe the drivers' strategies for getting rides, and subsequently their reasons for engaging with Ola.

\subsubsection{Getting rides and reaching earning targets}

The biggest challenge that auto rickshaw drivers face is finding enough passengers to be able to achieve their target income for the day. Rides are not evenly distributed throughout the day and are subject to the 'rhythms of the marketplace' (Ahmed et al., 2016). The drivers reported that they get a decent number of rides 
in the morning before the rush hour. During rush hours, typically 09:00-11:00 in the morning and 17:30-19:30 in the evening, there is high demand for auto rickshaws and cabs, but the drivers get stuck in traffic congestion and cannot take on as many rides as they would want to. In the lean hours (11:00-16:00), there is not enough demand from the customers' side. Therefore, the drivers choose to either wait at certain 'hotspots', where they know they are likely to get passengers (near shopping malls, hospitals etc.), or just keep 'rounding' till they are hailed by a passenger off the streets (Ahmed et al., 2016). Drivers strategize and weigh the trade-off between 'rounding', which entails fuel costs, and waiting, which might mean a loss of time and money if they do not get any rides. Some of the key factors that drivers deliberate upon when making decisions on whether or not to accept a ride are traffic density, knowledge of different parts of the city, and the risk of 'dead-heading' - coming all the way back empty after completing a ride because they could not find a return ride (See Glöss et al., 2016). While some drivers preferred long-distance rides as only a few such rides are enough to achieve their daily target, the risk of 'dead-heading' incurring fuel costs and loss of alternate rides lead other drivers to prefer shorter rides within a certain radius. Yet others did not refuse any rides and undertook a mix of 'short' and 'long' rides. Drivers constantly weighed these trade-offs and made decisions to maximize their daily target within their working hours.

\subsubsection{Joining Ola}

The drivers' initial motivation to join Ola was the prospect of getting more rides, help them minimize idle time, and reduce the time spent 'rounding' without result. They believed Ola would also get them 'return rides' in case they went on 'long' rides, thus mitigating, if not eliminating, 'dead-heading'. On top of it all, Ola offering incentives for taking each ride was the icing on the cake for the drivers.

The incentive structure was reduced over time, however. At the time of the study in 2015, Ola offered 40 INR (approx. \$0.6) per each 'Ola ride' taken during rush hours and $10 \mathrm{INR}$ per ride during lean hours. However, the rush hour traffic incentive of 40 INR per ride could be availed only upon the driver completing three such rides (i.e. 120 INR or $\$ 1.8$ would be provided as a lump sum). If the driver, because of traffic conditions or a long ride, could not complete three rides in that period, he would not get any incentive at all. Drivers also reported that Ola offered an incentive of a 1000 INR (approx. \$15) if a driver used Ola for 12 hours a day for seven consecutive days:

'My friends told me about Ola. They said they would get more rides and Ola gives them an incentive. I found it quite useful because 1000 rupees per week is a lot of money. Initially Ola would provide us 1000 rupees a week. Subsequently, they stopped it. They now give 40 rupees per ride between 5-10 pm. At other times, we get 10 rupees per ride. However, we have to take a minimum of three rides for either.' (Driver P11)

Not all drivers were clear on the incentive structure and different drivers reported different incentives to us. This is because Ola changed its incentive structure 
frequently and drivers did not always have a precise idea of the incentives that were being offered. They did have a clear feeling, though, that Ola's incentives had decreased considerably over time.

The overall expectation to get more rides through Ola had remained largely unfulfilled, according to the drivers' statements, although a couple of drivers reporting initially good business when Ola was first launched, with a downturn recently. The number of Ola passengers' drivers reported taking varied highly, from 'not enough' or one a day to more Ola than passengers off-the-street. However, the unpredictability remained. Driver responses were mixed on whether or not Ola had improved their earnings. Some reported that their daily earnings had increased after joining Ola by 100-200 INR (approx. \$1.5-\$3) whereas others reported that they had seen no difference. However, what is more significant for our analysis is the source of increase in earnings of the former group. Going by their initial motivation, one would expect that Ola had enabled them to get more rides and, therefore, their incomes had gone up. That was not the case, even for those drivers who reported an increased income. Rather, they attributed the increase to the incentives that Ola offered. Ola did not increase their passenger numbers, because, in effect, they exchanged passengers on the street for Ola passengers, and drivers consequently depended on both to make a living. To quote driver P2,

'I keep getting rides in the morning. At that time, I will have passengers on the streets itself. When I am free, I do not get (Ola) rides at all. When I get passengers on the street, who will go 1-2 km to pick up somebody else from Ola? I cannot rely solely on Ola to get me my daily earnings.'

\subsection{Ola Money, Cash and Financial Practices}

After adopting Ola, driver's earnings changed from cash-only to a mixture of cash and digital payments. The passengers they picked up off the streets paid exclusively by cash, whereas Ola customers paid either in cash or digitally using Ola Money. Drivers reported different estimates for how many Ola passengers paid digitally from $10-20 \%$ to one driver (who reported getting 3-4 Ola rides a day) who estimated half paid digitally. Since driver's income came from a mixture of street passengers and Ola passengers, who themselves mostly paid via cash, only a small fraction of their daily earnings came in digitally. Drivers had two sources of digital income; 1) ride payment via Ola money, and 2) incentive payments via bank transfer. Drivers had quite different understandings about when the money is transferred into their bank account, with drivers reporting immediately, every two, or three to four days, or once a week on Tuesdays. We asked Ola about this and they told us that drivers received their ride payments daily and their incentive payments weekly. Whatever the reality, it is clear there is lack of transparency about this. The majority of drivers knew they could see their earnings on the Ola app itself, although two mentioned that they could not see them through the app and needed to check at the bank.

Whilst drivers did get paid digitally, they were unable to do anything digitally with that income, neither through the Ola Money nor through the bank account. 
The bank account that Ola had opened for them was not a fully transactional account and could not be used for deposit or savings. In effect, it was an Ola account simply to receive digital payments. Once received, drivers were limited to withdrawing it as cash from the ATM.

Drivers had mixed opinions about whether they preferred to be paid by Ola Money or cash - it was fairly evenly split between drivers preferring Ola Money and those preferring cash, with two being indifferent. However, this was based on the current mix of cash and digital payments and P12 sums it up well:

'I don't mind being paid by either but if everyone starts paying with Ola money how will we send money home and take care of other expenses? If 2-3 people pay by Ola money in a day, it is fine.'

Drivers remained cash dependent for a variety of reasons: 1) Because of the socioeconomic networks they operated within, the majority of their day-to-day expenses required cash, because mom and pop shops, hotels (eating places), chai stands and so on which they frequent are still largely cash-only; 2) Since drivers often struggled to earn enough meet their day-to-day financial needs, the lack of realtime bank transfer of their earnings tying their money up was frustrating. As P1 reports, '[Ola Money] doesn't come of use to me because the bill doesn't get passed [to his account] for 2-3 days. I will have daily problems too'; 3) Their incomes were small, daily, and uncertain, as P1 sums up:

'If it were a monthly salary, then we would know beforehand how much money we are going to earn in a given month and can therefore adjust our commitments accordingly. Since our earnings are on a daily basis, and there is uncertainty about how much we earn on a given day, it is difficult.'

Drivers, therefore, had to balance their need for adequate cash flow, and actual cash. In doing so, drivers were occasionally reluctant to accept Ola Money and depending on how much they had earned that day in cash, they would decide whether or not to accept digital payments. They would sometimes ask the Ola customers to cancel the ride or cancel it themselves, if the customer was unwilling to pay by cash, as P1, again illustrates, 'So, I tell the passengers 'Please pay me the amount itself, Sir'. Notwithstanding the issues they faced, drivers said that it was important to be considerate and understand any potential exigencies of customers. To quote driver P3:

'It is not fair to expect each and every passenger to travel with cash at all times. We do not know why they do not have cash. They might have left their home in a hurry for some emergency. Therefore, we have to accept the use of Ola Money by some passengers. Furthermore, it is not as if they are running away with our money. The amount will get deposited into our account.' 
Drivers were not against digital payments per se but were sensitive to the requirement to balance both cash and daily needs. Even P3 who stated that he preferred passengers paying in cash to Ola Money said of passengers letting them know in advance when they will pay by Ola Money 'It's good that they do this because it's not right to go to the pickup address and then fight about cash or Ola money.' That is, even the preference for Ola Money over cash is only given in light of this mixed income. This preference would not hold if all the money was paid digitally.

\subsubsection{The advantages of digital payments}

When we probed drivers on what they did with the money they received digitally, some interesting findings came to the fore. Almost no drivers, even those stating that they preferred cash, said they withdrew their money immediately when they received it. For example, P1, despite mostly requesting passengers to pay in cash went on to explain how he used his Ola Money account 'I always withdraw when there is an emergency. The most it has accumulated to is Rs 2000. I have some problems at home here and there, that's when I withdraw.' To put this in context, it should be noted that 2000 INR (approx. \$30) is more than what most drivers had accumulated in their personal bank accounts as savings. Of the ten drivers willing to give us details, four said they withdrew periodically, mostly weekly to pay their auto-loan or auto expenses or house rent; five said they withdrew it when it was needed or in an emergency, and one had never withdrawn, having a current balance of around 3500 INR (approx. \$50). Digital payments, therefore, delayed immediate spending and, thus, worked as a kind of short-term saving (even if drivers did not always describe it as saving), but at the same time, the ATM card still enabled them to withdraw it as and when they needed it. As P3 reported:

'I prefer passengers using Ola money over cash because with Ola money, the amount goes into my wallet which gets saved up. If it's cash, it gets spent away.

I feel secure when I know I have some money in my Ola wallet.'

Digital payments supported saving because of the delayed availability and the extra effort of accessing it via an ATM, whereas the immediate availability of cash and its acceptance everywhere made this form of money preferable for everyday monetary transactions. These findings are rather different from other research into digital payments for low income communities which typically found that receivers withdraw the entire amount in cash as soon as it had been received (Blumenstock et al., 2015). The reason for this difference stems from the mixture of cash and digital incomes.

\section{Discussion}

Our study shows that the mediated bank transfer system, whereby drivers receive both digital earnings and incentives, offered a mix of advantages and disadvantages to the drivers. 


\subsection{Money-guarding}

The transfer of some of their income to a bank account via the Ola Money wallet meant that drivers had to perform additional work for withdrawing their income via an ATM. However, this extra work of digital-to-cash conversion was acknowledged by drivers as helping them to 'save' in an intermediated way. This is because they operate with a mix of physical and digital forms of money and earmark each for specific needs and purposes. Because of these 'earmarking' practices, the technology together with the bank account take on the role of a 'money-guard' (Mas and Morawczynski, 2009). This provides a useful additional form of 'money-guarding', in addition to informal savings groups; each of which has its own purpose, and each of which is well needed, and bears out previous findings that low income communities often use many different financial instruments as a way of making barely sufficient, or blatantly insufficient, incomes stretch (Collins et al., 2009). The technology-mediated bank transfer might be seen to have some advantages, over informal lending, when it comes to safety and trust as drivers can immediately check their Ola Money balance from their smartphone ${ }^{9}$. Issues of digital literacy or usability were quickly overcome. Even where drivers initially found Ola and Ola Money hard to use, they were able to pick it up with the help of their peers. While still preferring cash, our findings indicate that drivers are not anti-digital money as such and appreciate some of its affordances. Their financial practices enabled digital money to act as an 'accumulator' of savings in the short- to mid-term for the drivers by taking on the role of a 'digital moneyguard'. Driver P4's statement illustrates the benefits nicely:

'I withdraw money from my Ola wallet every Monday... (when) I make payments towards my loan. Before Ola, I would have to struggle for 2 days just to earn the weekly payment amount. With Ola, I just have to set aside 200-300 INR (approx. \$3-\$4) per week. The rest of the money is paid with the money that is saved over the week through Ola Money.'

Our findings also highlight the fact that low-income groups' acceptance or refusal of digital payments is not always related to issues of transparency or trust as has often been raised in connection with digital money (Vines et al., 2011; Panjwani et al., 2013; Ghosh et al., 2015; Donovan, 2018). Rather, in our case, drivers' preference for cash versus digital payments stemmed from their immediate needs for cash flow, and for cash, as well as the desire to hold back some money once these immediate needs were met. Since drivers even struggle to save cash for a week (O'Neill, Dhareshwar, and Muralidhar, 2017), the Ola account helps them keep money aside whether for larger weekly (or monthly) outflows (rent, loan payment) or unexpected expenses such as medical emergencies that need pooling of resources. Drivers preferred digital money in these cases as it was easier to save than cash. At the same time, short-term expenses like fuel, food, and household

\footnotetext{
9 This is not to say that the question of trust has disappeared altogether. The drivers still have to trust Ola to pay their digital earnings and incentives, and the drivers certainly did not fully trust Ola in this. However, the technology at least provides more visibility into their earnings, once it has been paid out.
} 
goods demanded immediacy of resources, not quantity, and, hence, cash was preferred. Even in the case of day-to-day expenses, the problem was not with digital money per se, but with a combination of the restrictions put onto drivers such that they could only convert digital payments to cash via the ATM in order to spend it (thus necessitating a visit to the bank), and the lag in the transfer of their earnings. Other studies have also reported similar delays (of up to a week) in case of Uber in the UK and US (Glöss et al., 2016). Similar to their participants, our drivers also did not understand why their earnings were not made available to them in real time (or at least by the end of the day).

It is important to note here, then, that two findings are missing from the discourse on digital or mobile money and financial inclusion. Firstly, in this case, digital payments help drivers to set aside money, because they make up only a minority of their income. That is, it is the mixture of cash and digital payment which gives digital money its advantage. Secondly, the two downsides of the current system that the money only comes in occasionally and then can only be withdrawn in cash - are also what gives digital money its stickiness and enables the Ola account to act as a money-guard. This works as long as they are earning enough in cash to manage their everyday needs. Furthermore, if they were paid immediately and could use the Ola app to pay for their day-to-day needs, digital money would most likely lose its stickiness. In this case, whilst digital money might be argued to be increasing the financial well-being of the drivers (even where they did not like it, particularly), its advantages are incidental: the results are not of digital money per se, but of this particular set of contextual factors and, crucially, the fact that drivers are not fully integrated into the digital money ecosystem. If they were fully integrated into a digital money ecosystem, i.e. could use their money digitally, then digital money would provide little additional benefit.

\subsection{Agency and control}

Auto-rickshaw drivers, being self-employed, cherish the autonomy that their job brings. However, it also means that they do not enjoy fixed, stable, regular incomes. Although government regulations determine the auto-rickshaw fare (the minimum fare as well as fare per each additional kilometre), in practice, drivers sometimes negotiate the fare with their customers on the fly. If there are possibilities of being stuck in traffic or 'dead-heading' back to the same point, then they typically ask the customer to pay a little more than the meter rate ${ }^{10}$ (ranging from a flat rate of 1020 INR to $1.5 x$ the meter rate ${ }^{11}$ ).

This autonomy was reduced with the advent of Ola. Government regulations and fares gave the drivers at least a semblance of financial stability, and while it officially barred negotiations for 'something extra', it did allow drivers to make estimates of how much they might earn for a given ride, which in turn, shaped their strategies for short-rides, long-rides, and so on. The fares were revised periodically

\footnotetext{
10 There have been occasional cases where drivers have demanded a lot more and customers have lodged complaints to the traffic police. However, this is not common.

$111.5 \mathrm{x}$ is also the standard nighttime fare (from 22:00 to 05:00 hours) as per traffic regulations.
} 
by the transport authorities in negotiation with union representatives, taking into account factors like inflation, and thus, drivers had a voice in shaping the policy and determining the fare. Previous studies have also noted how meter-based fares were perceived as 'just' and 'fair' by passengers as well (Civitas, 2010; Chanchani and Rajkotia, 2012). With Ola, the platform sets the fare for any given ride by engaging in 'algorithmic pricing', which is opaque to both drivers and customers. Studies on Uber and 'surge pricing' (pricing based on demand or time) have reported similar concerns and questioned, for example, Uber's claim that 'surge pricing' will attract drivers to busy areas during peak hours and create additional income (Lee et al., 2015; Glöss et al., 2016). Rather, in contrast to Uber's claim, 'surge pricing' has been shown to have a negligible impact on attracting drivers and largely results in driving customers away from the 'surge areas' because of the price-difference (Chen et al., 2015).

'Algorithmic pricing' can be argued to be unfair to both customers and drivers. Ola does not reveal the 'service fees' or 'processing fees' it levies to the customers, unlike other platforms like Airbnb. Consequently, customers have no way of knowing how much of their fare went to the driver and how much of it to the platform. On the driver's end, 'algorithmic pricing' adds a new layer of uncertainty to their already-precarious financial situation as they can no longer predict or estimate how much a given ride might fetch them. Furthermore, the Ola system design further constrains customers and drivers' actions: In the Ola customer app, when a person books a ride, the app expects him/her to choose the mode of payment before the ride is booked. If the person has no Ola Money balance in his/her wallet, it prompts them to choose to either top up their wallet or pay by cash. The implication is that Ola customers are forced by the system design to make a choice before they even get a chance to contact or meet the driver. Even in cases where drivers ask if the customer is going to pay by cash, it is already too late for them to go back and change it. What this discussion illustrates is that drivers engage in a 'triple negotiation': with the customers, the platform, and the government.

\subsection{Constraints on digital transactions: Drivers and Customers}

What complicates the scenario even further is that, in case of digital payments and pay-out of incentives, it is the platform provider that solely decides what the incentive structure should be as well as the money transfer period. The one-week delay is, in some ways, a lock-in period. On the one hand, Ola customers have the option to pay via cash or Ola Money. They can load up their mobile wallet using a debit- or credit-card, or internet banking. They can also link their bank account or card to their Ola account and authorize automatic debit for top-up ${ }^{12}$. On top of it, Ola launched 'Ola Credit' in 2017 for its customers ${ }^{13}$. 'Ola Credit' is a policy where customers, who find themselves unable to pay for a ride because they do not have

\footnotetext{
12 This is the norm in the West where Uber rides are paid for by a credit card that is linked to one's Uber account. Because India is a predominantly cash economy, both Uber and Ola offer cash payment for rides.

13 https://blog.olacabs.com/more-about-ola-credit/
} 
sufficient Ola Money balance or cash, can obtain credit from Ola on the fly and pay for the ride. Ola allows its customers to take rides for up to a week on credit, by the end of which they have to repay.

On the other hand, we have the drivers who have been given a bank account that is not fully transactional and can only be used for withdrawing Ola earnings, but not for savings or deposits. Thus, they cannot 'use' Ola Money in an active, transactional sense to pay for their gas, electricity, or groceries, which works against the use of digital money in this case. Whereas customers (at least those who have internet banking or debit/credit card) can top-up their Ola Money balance digitally, the rickshaw drivers cannot 'use' their Ola money digitally, but have to convert it to cash. Mainwaring et al. (2008) point out that 'money works best when it works towards people's varied ends' (p. 21), and stress the need for system design to support users' management of their money without placing new or additional burdens on them. However, in this case it seems that Ola's design was aimed at supporting customers, rather than drivers. This is perhaps no surprise as previous research has detailed a variety of ways in which the design of the system privileges customers over workers, for example in the design of ride acceptance, where the driver does not get to see the drop location when accepting (Ahmed et al., 2016). This is apparently so in order to prevent cherry-picking, or in the rating systems (Lee et al., 2015; Rosenblat and Stark, 2016; Ahmed et al., 2016; Shapiro, 2017), which entail additional 'emotional labor' on the part of drivers to adapt to customers' needs and conform to their expectations (Raval and Dourish, 2016; Rosenblat and Stark, 2016). In terms of payment in the platform economy, much work in the crowdsourcing space has pointed to the lack of transparency in job acceptance or rejection by the customers/platforms. When jobs are rejected workers are not paid, thus they engage in extra (unpaid) work to ensure they do the work correctly (Bederson and Quinn, 2011; Felsteiner, 2011; Silberman, 2010; Silberman, Irani, and Ross, 2010; Martin et al., 2016; Morozov, 2014; Isaac, 2014). Prior to tipping being introduced by Uber, Rosenblat and Stark (2016) describe how drivers now perform emotional labor for ratings instead of tips, thus reducing possible income from any ride. Gloss et al. (2016), in their discussion of Uber in UK, note that drivers were frustrated by the fact that Uber transferred their earnings (which were exclusively digital, paid via credit card, unlike in India) on a weekly basis. This meant drivers struggled to manage fuel expenses and vehicle maintenance costs. In this paper, we have explicated the consequences of platform design, which privileges customers over drivers, on financial inclusion.

\subsection{Design implications}

There are several ways in which the P2P platform of Ola could be redesigned in ways that would benefit drivers. First, Ola could make the transfers to drivers' accounts happen in real time, which will support drivers' agency and control over their financial lives, and still allow the platform to act as 'digital money-guard', because the transfers will be done to a bank account and not via cash, and digital to cash conversion would continue to be required. Also, real-time transfers would probably make drivers more accepting of digital payments and reduce friction 
between customers and drivers. Second, at the customer-end, we recommend some changes to the mode of payment design: Instead of forcing the customer to choose the payment method before a ride commences with no possibility of reverting or changing the choice, the choice of payment method should be moved to a later point i.e. any time before the completion of the ride. Even if the customer has chosen a certain payment method, he or she ought to be able to change it upon the driver's request or by his/her own volition. This will also reduce any potential conflict between drivers and customers and enhance their user experience. Third, we suggest that Ola should make the bank account fully transactional. Allowing drivers to carry out other transactions like transfers, remittances, and deposits, ideally through the Ola app, might remove the stickiness of the current arrangement, but gives drivers more autonomy over their money. It might also be possible to give drivers more flexibility in how they organize their accounts to ear-mark digital money if they wish, thus recreating the current stickiness. Of course, this would necessitate Ola working with banks to make internet banking services accessible to drivers and is non-trivial, but could really be an important step towards their financial inclusion. In this context, it is also recommended that Ola should not necessarily open up new accounts for those drivers who already have one if they prefer to use existing accounts. Mere ownership of several bank account(s) will not help achieve financial inclusion and might instead entail extra effort in managing finances and make it difficult to have an overview of their financial situation. More accessible, affordable, and convenient services are needed instead of more, new bank accounts.

\section{On financial inclusion and digital money}

We conclude this paper with some wider reflections on financial inclusion and digital money, and P2P platforms that mediate work and financial practices. Our discussion of the implications for financial inclusion come from the addition of this case study to prior work, in particular, the work on bank accounts (Morawczynski et al., 2010; Medhi, Ratan, and Toyama, 2009) and mobile money (Blumenstock et al., 2015; O'Neill, Dhareshwar, and Muralidhar, 2017). In doing so, we call for a rethinking of financial inclusion to move beyond access and to explicitly include the overarching objective of improving financial wellbeing. Furthermore, we propose to add the concepts of 'autonomy' and 'affordances' to the five A's described by Saurabh (2017). Finally, we discuss the prospects and challenges in working towards building a more inclusive digital economy and make recommendations on how P2P platforms can enhance drivers' welfare.

\subsection{Conceptual broadening of 'Financial Inclusion'}

In discussions of financial inclusion, the distinction between 'access' and 'usage' is important, as mentioned earlier in the paper. In our case, rickshaw drivers did have access to a smartphone, digital money and bank account, but usage was 
restricted due to requirements of drivers to possess different kinds of money, and because of the constraints posed by the P2P ecosystem, and the way Ola Money and their bank account had been set up. We, therefore, join the calls of previous research to think beyond access (e.g. Morawczynski et al., 2010; Donovan, 2018). The question of 'inclusion'/ 'exclusion' becomes constituted as a binary when we think in terms of 'access', in this case access to formal financial services. It becomes too easy to fall into the trap of thinking of 'access' as an end in itself rather than the means to a larger end. 'Access' to formal financial services is a necessary but not sufficient condition. Looking beyond access, at usage for instance, enables us to look at practices, user appropriation, infrastructures, regulations, social networks and ties, power relations, and a host of other relevant factors that can help us better understand 'inclusion' and the role technology plays (or can play) in this regard. The 'formal'/ 'informal' binary is constituted similarly. The financial practices of rickshaw drivers reveal that these binaries are artificial ones. Even when they gain access to formal financial services, they do not completely switch over from one to the other. It is not an 'all-or-nothing proposition' (Taylor and Horst, 2018). Rickshaw drivers choose from a range of options at their disposal. Their choice of a particular channel or instrument is predicated upon several factors such as convenience, flexibility, accessibility and so on. Therefore, from a practicecentred perspective, bank accounts become only one point along a spectrum of products and services from which low-income users choose. Formal financial services will not replace informal services completely, nor is there any reason for them to do so.

The '5 A's' of financial inclusion that Saurabh (2017) highlights, namely: availability, accessibility, acceptability, affordability, and awareness (ibid, p. 37) broaden our understanding of financial inclusion in that they direct our attention to material aspects such as infrastructure (availability and accessibility), as well as social, economic and cultural aspects (awareness, affordability and acceptability). While these describe the 'what' i.e. the factors that ought to be considered when designing financial products and services (digital or otherwise) for low-income communities, they do not point to the end-goal of financial inclusion i.e. 'what for'. The question assumes significance when we look at recent discussions around how 'inclusion' can be detrimental, as can the use of even the flagship mobile money solution for financial inclusion, M-PESA. We will provide two brief illustrations here. First, in a study carried out with women's groups and visually impaired people in Kenya, Kiiti and Mutinda (2018) found that the use of M-PESA had a negative impact on the group dynamics of a women's ROSCA (rotating savings and credit association). Some members started sending money through M-PESA and stopped attending the meetings, which affected the social, participatory dynamics of group interactions. In the case of visually impaired people, the participants found MPESA to be inaccessible, which entailed sharing sensitive information like PINs with others for conducting transactions and had led to cases of fraud. Second, in a study carried out on digitization of welfare payments in South Africa, Donovan (2018) found that low-income beneficiaries gaining access to a bank account and a debit card or being 'financially included' had led to the emergence of new intermediaries who, first transformed the social grants into loan products, and then 
made use of automatic, electronic deductions from bank accounts, as loan repayment. This led to a disempowerment of the grant recipients. The legal, financial, and technological changes that were constitutive of 'financial inclusion' were perceived as diminishing the autonomy of the beneficiaries by pro-poor advocacy groups. 'Pensioners did not understand what was happening to their grant money and their unfamiliarity with the new technology only magnified the confusion' (ibid, p. 164).

In this study, it is the interrelation between digital money and cash which gives digital money any benefits it has, not some inherent properties of digital money alone. This study provides a new instance which reinforces our earlier findings (O'Neill, Dhareshwar, and Muralidhar, 2017) that digital payment and use of digital money, at least in India, is often siloed. That is, low income populations tend to use one service for only one purpose, which they adopt out of necessity. Lowincome communities are often part of multiple disconnected ecosystems, and in this case the Ola Money ecosystem was disconnected by design. This does not necessarily lead to financial advantage for the users, and where it does, such advantages are typically incidental rather than fundamental. The research into the use of different mobile money systems by low income communities has shown that moving from one service to another does not necessarily improve financial wellbeing, and that digital is not inherently better as people just withdraw all their money (Blumenstock et al., 2015), or use mobile payments just for one specific thing (O'Neill, Dhareshwar and Muralidhar, 2017), or their use is tied into wider infrastructures.

The question, therefore, remains - what is it that we are trying to achieve with 'financial inclusion', whatever we mean by it? We would argue that the goal of financial inclusion is to improve the financial wellbeing of low-income populations, and we, therefore, call for definitions of financial inclusion to explicitly embrace this notion. Whilst financial wellbeing may be hard to measure, whereas access is easier to measure, it has become increasingly clear that access whether to bank accounts (Morawczynski et al., 2010) or mobile money (Blumenstock et al., 2015; O’Neill, Dhareshwar and Muralidhar, 2017) is nowhere near enough or even detrimental (Donovan, 2018).

If access is the financial inclusion problem we are trying to solve, then digital or mobile money, in and of itself, makes sense as the answer. We only have to take a look at the example of the drivers' Ola bank account to see why this is problematic. In terms of access, Ola has achieved financial inclusion: they opened an account for drivers and paid them digitally into it. In reality, however, it is clear that Ola made no attempt at financial or digital inclusion in designing their payment system. If we consider instead financial wellbeing, working for Ola has done little to improve drivers' income, and the benefits of the digital payments were incidental rather than by design, and ironically came from the same features which mean that drivers remain on the periphery of the digital payment ecosystem. Ola certainly expresses a desire to work for the benefit of the drivers, and recently introduced a scheme, 'Auto Unnati' which aims to support drivers' welfare - including in-ride insurance and "guaranteed" earnings of 40,000 INR (Economic Times, 2018). If these earnings in reality live up to their promise, they are likely to contribute more 
to the financial inclusion of auto-rickshaw drivers than even full integration into any digital payment system, and when considered like that, it is perhaps myopic to think that any mere technology can 'include' people if it does not contribute to increased income or reduced outgoings.

Returning, then, to the 'what for' of financial inclusion, we suggest adding a sixth 'A' towards which any financial inclusion agenda must work if it is to act as a driver of social change and improve financial wellbeing: autonomy. Financial inclusion must enable or eventually lead to greater financial autonomy of the hitherto marginalized and excluded communities. This builds on Amartya Sen's framework of 'development' as enhancement of people's capabilities - a state of freedom and opportunity where people can make informed, meaningful choices and decisions, and improve their life outcomes (Sen, 1999).

In the context of digital technology enabling financial inclusion, a seventh 'A' affordances (Norman, 1988; Gaver, 1991; Gaver, 1992; Sellen and Harper, 1997; Kaptelinin and Nardi, 2012) - ought to be included. The properties of different kinds of artefacts (such as mobile phones and money) are important for the possible actions that users can perform with them and exert an important influence on user acceptance and appropriation ${ }^{14}$. Here we can see that it is not access to formal financial products and services per se that enable greater financial autonomy, but rather the technologies and infrastructures upon which financial products and services operate that enable new possibilities (Musaraj and Small, 2018). In the context of digital payments and financial inclusion, highlighting the affordances of the different media (cash, cards, mobile phones etc.) and crucially the services provided on and around these media (Ola Auto, Ola Money, bank accounts) takes us beyond the oversimplified cash-digital dichotomy, and enables us to better understand whether and how different services built on top of different technologies might contribute, or otherwise, to financial inclusion.

Making the bank account fully transactional (and not a debit-only account) will enable drivers to transact with their bank accounts actively ${ }^{15}$, whereas opening up the mobile wallet (similar to the customers) and enabling drivers to make P2P transfers, bill payments, and mobile recharges, could reduce the cash-dependence of drivers and, depending on the charges levied, might reduce costs ${ }^{16}$. Enabling drivers to transact more digitally with their mobile wallet will further augment efforts in creating a digital financial history for them, and a first step in this direction could be for platforms and the government to collaborate with gas stations to accept digital payments, given these are places drivers frequent on a day-to-day

14 There is a vast body of literature in HCI and CSCW on affordances. Sellen and Harper (1997), for instance, discuss the affordances of paper in knowledge work. Kaptelinin and Nardi (2012) undertake a critical review of some key interpretations of 'affordances' in HCI and outline a view of affordances as 'possibilities for mediated human action'.

15 This is not to claim that the drivers will automatically start transacting with their accounts actively and frequently. The argument is merely to create the necessary preconditions before such activity can be conducted.

16 In India, bank regulations permit only a limited number of 'free' withdrawals from ATMs per month. If the limit is exceeded, then each withdrawal will attract service fees. Cards also attract fees at PoS terminals like gas stations, which make them an impractical alternative for drivers. 
basis. Of course, this has the potential to reduce the stickiness, or money-guarding properties, of the current combined digital-cash system.

\subsection{Steps of inclusion into the digital economy}

Koh et al. (2017) propose a four-stage model towards achieving an inclusive digital economy. While the model is based on differences between countries and mostly examines benefits for the unbanked, it is also useful for more micro-level examinations and for considering the 'under-banked'. While 'unbanked' implies not having a bank account, the 'underbanked' refers to those who do have a bank account but do not have access to all of its facilities (like debit/credit cards, internet or mobile banking) that more privileged classes often take for granted (Vines, Dunphy, and Monk, 2014; Nandhi, 2018). This distinction helps us identify better the possibilities and challenges in designing digital financial services that fit with the needs and financial practices of low-income groups.

The objective in the first stage is to provide internet and mobile connectivity, and prior to the adoption of Ola, auto-rickshaw drivers were arguably in this stage. They used feature phones without data. Their activity with phones was restricted to calling and SMSs. With the entry of Ola, a majority of our participants found themselves using a smartphone and accessing the Internet for the very first time, although, due to the locked phone, only for Ola. In the second stage, a basic payment system is created, building on the basic infrastructure set up in stage one. Here, the situation is a bit more nuanced for the drivers, since they have been provided with a bank account and there is a mobile wallet, but the system design forces them to remain passive recipients not transacting users. This has prevented active participation in the digital payments ecosystem or with banks, and as already suggested, there is a need to redesign the system to encourage practices around using mobile phones as transactional devices, not just communication devices.

In the third stage, a full range of digital financial services that go beyond payments are available and the main challenge is interoperability. The opportunity to create such an interoperable ecosystem in India certainly exists, but in practice, the ecosystem created by P2P platforms like Ola and Uber is not open, and instead payments are enforced, by design, to be routed through the platform. This enables them to claim fees and deductions, which would not be possible if drivers and customers transact by cash or third-party payment applications (e.g. credit cards, Google Pay, PayPal, etc.), since these payment options would allow drivers and customers to bypass platform's mediation of economic exchange. The system design, which forces the customers to pay (thereby also forcing the drivers to accept) via cash or Ola Money only, puts the platform at the centre of the ecosystem ${ }^{17}$. Such an opaque, closed ecosystem tightly controlled by the platform is unlikely to result in greater financial autonomy for drivers, and presently drivers

17 Even in case of Uber, which does not have its own m-wallet, all card-based payments are routed through the platform. Glöss et al. (2016) point to a 1-week delay in disbursing digital earnings and incentives to drivers in London and San Francisco. 
are stuck somewhere between the second- and third- stages in this model for various reasons, which need to be addressed in order to proceed to the next stage.

\subsection{Government, P2P technologies, and financial inclusion}

It is important to understand that $\mathrm{P} 2 \mathrm{P}$ platforms like Ola are uniquely positioned in the Indian ecosystem to leverage technology for creating a durable, digital footprint for their drivers at scale. Big data analytics has been argued to help with risk assessment of low-income, unbanked groups (Sun, 2017). These platforms collect data on both drivers and customers as part of their everyday practices. They have access to both micro-level data on individual drivers, number of rides they took, earnings, and so on, as well as more macro-level data such as percentage of customers who pay digitally, city-to-city comparisons and so on. No other actor is privy to this data for obvious proprietary reasons. However, this data could be put to use to create a digital financial history and build a credit rating for the drivers. Drivers are a socio-economic group of workers who have historically worked exclusively with cash and mostly in 'informal' channels. Because they are selfemployed workers earning a daily income, neither government nor banks have historically had substantial data on their work or financial lives. This has created obstacles for the drivers when trying to obtain loans for vehicles or some other purpose in banks. For the first time, they are in the midst of technological infrastructures that will enable creation of digital financial history for them that might facilitate obtaining credit and other financial services with regulated institutions in the future. Even if platforms like Uber and Ola cannot accurately determine their precise earnings, they collect sufficient data day in day out to provide good estimates of how much drivers earn on average. By making the bank account as well as the mobile wallet fully transactional, it would be possible to obtain a rich picture of not only drivers' earnings but also the cash outflows. Digital infrastructures enable us to overcome the material constraints that paper records entail and ensure durability. Whether such infrastructures ultimately contribute to creation of financial records that might ease access to credit or lead to data trails resulting in concerns over privacy depend, at some level, on intent. What is important here is for governments and other institutions to take stock of the ability we have today that could be harnessed to help low-income, marginalized communities.

As far as the financial needs of low-income groups are concerned, access to both long-term loans as well as short-term credit has been identified in the literature as one of the pressing needs that need to be addressed. The worldwide microfinance revolution has, in fact, been based on this idea (Roy, 2010). As discussed earlier, auto drivers face bureaucratic as well as financial hurdles when purchasing a new auto rickshaw. Through social and community networks, drivers often overcome the bureaucratic hurdle and obtain permits. However, because of a lack of credit rating, banks are typically unwilling to lend to them to purchase their rickshaws (Bhattacharya and Singla, 2007; O'Neill, Dhareshwar, and Muralidhar, 2017; Mehra et al., 2018; Muralidhar et al., 2018). Organizations like Three Wheels United (TWU) help them obtain loans by acting as intermediaries (ibid). That said, 
providing access to credit will not suffice by itself, since previous research has shown how loan payments by low-income communities involve tremendous work in collaboration with other actors (O'Neill, Dhareshwar, and Muralidhar, 2017; Muralidhar et al., 2018). Nonetheless, obtaining access to credit is an important step that needs to be addressed first. While Ola is certainly well positioned to collaborate with banking institutions and facilitate provision of loans to purchase auto-rickshaws or arrange for short-term credit, to what extent it will actually benefit drivers will depend on Ola's intent and implementation of such an initiative. It is, therefore, important not to lose sight of intent while taking stock of platforms' ability to help the drivers.

With respect to supporting management of day-to-day finances, we suggest that Ola should provide a weekly or monthly overview of drivers' finances on their app. Because drivers' information about their rides, earnings and so on is shown for individual rides, drivers do not have access to a concise overview of how much they earned in a given week or month, how many rides they undertook, what incentives were disbursed and so on. Of course, not all rides that drivers undertake in a day come from Ola (or Uber). Nonetheless, providing such aggregate figures on their dashboard can help them get a better sense of their finances and support strategies for managing their household needs and expenses.

Toyama (2015) argues that technology acts as an amplifier of human intent and ability. With the emergence of P2P platforms, we have seen technology amplify businesses' ability to create new business models based on 'flexible' labour in poorly regulated markets (Gupta et al., 2014; Raval and Dourish, 2016; Irani, 2015; Martin et al., 2016). Technology amplifies intent as well. Insofar as the intent of private operators like Ola and Uber is oriented towards profits and not creation of an inclusive ecosystem, drivers are facing problems in different parts of the world (Ahmed et al., 2016; Glöss et al., 2016; Rosenblat and Stark, 2016; Shapiro, 2017). Our belief is that this does not have to be so. Governments ought to take stock of this and realize that there is the ability to create an open, inclusive ecosystem that performs the dual functions of connecting drivers and customers and enabling digital payments in real time in a non-zero-sum way. There are several ways by which current problems can be overcome. First, governments can enforce stringent regulations such as provision of insurance for drivers (as they have done in France), and price regulation that is fair to both customers and drivers. Second, they can launch their own platform possibly in collaboration with unions or encourage member-driven initiatives, and provide the necessary financial and technological support, if existing platforms like Ola and Uber do not adhere to the regulations and walk out.

The hope for digital money to further financial inclusion and for $\mathrm{P} 2 \mathrm{P}$ platforms to benefit self-employed workers, whether unbanked or underbanked, is predicated on how these infrastructures are designed. As the present case of the financial practices of rickshaw drivers in Bangalore shows, this financially vulnerable group has different financial strategies to ensure a daily income and manage short as well as long-term financial requirements. Doing this, they make use of the various affordances of cash and digital money but are also limited by both the design of Ola Money and of the bank account. For CSCW, our case contributes to the ongoing 
discussion of how work and employees' work conditions are shaped, constrained and augmented through digital systems, including P2P. Technology itself does not entail better futures, and paying close attention to how technologies are designed and closely analysing how they support work through detailed, empirical studies is required. Our case, raises crucial questions as how to design $\mathrm{P} 2 \mathrm{P}$ to benefit financially vulnerable groups, and extends the notions of financial inclusion in order to better direct strategies and technology design towards the end of wellbeing.

\section{Acknowledgments}

We would like to thank both Three Wheels United and Peace Auto for helping connect us to the auto-rickshaw drivers and Peace Auto for providing office space for interviews. Most importantly we would like to thank all the auto-drivers who generously gave us their time and insights.

\section{References}

Ahmed, Syed Ishtiaque; Nicola Bidwell; Himanshu Zade; Srihari Muralidhar; Anupama Dhareshwar; Baneen Karachiwala; Cedrick Tandong; and Jacki O'Neill (2016). Peer-to-peer in the Workplace: A View from the Road. CHI'16: Proceedings of the SIGCHI Conference on Human Factors in Computing Systems, San Jose, USA, May 7-12, 2016. New York: ACM Press, pp. 506375.

Banerjee, Abhijit; and Esther Duflo (2011). Poor Economics: A Radical Rethinking of the Way to Fight Global Poverty. New York: Public Affairs.

Bederson, Benjamin; and Alexander Quinn (2011). Web workers unite! Addressing challenges of online labourers. In B. Begole and W. Kellogg (eds.): CHI'11 Extended Abstracts on Human Factors in Computing Systems, Vancouver, Canada, May 7-12, 2011. New York: ACM Press, pp. 97-106.

Bhattacharya, Jaijit; and Richa Singla (2007). Microfinance - A Technical Framework for Cross Border Credit in India. ICEGOV 2007: Proceedings of International Conference on Theory and Practice of Electronic Governance, Macau, China, December 10-13, 2007. New York: ACM Press, pp. 179-182.

Blumenstock, Joshua; Michael Callen; Tarek Ghani; and Lucas Koepke (2015). Promises and Pitfalls of Mobile Money in Afghanistan: Evidence from a Randomized Control Trial. ICTD'15: Proceedings of the Seventh International Conference on Information and Communication Technologies and Development, Singapore, May 15-18, 2015. Article 15. New York: ACM Press, p. 15.

Braun, Virginia; Victoria Clarke; Nikki Hayfield; and Gareth Terry (2012). Thematic Analysis. In Harris Cooper (ed): APA Handbook of Research Methods. American Psychological Association, pp. 843-860.

Center for Financial Inclusion (2016). Our Definition of Financial Inclusion. http://www.centerforfinancialinclusion.org/about/who-we-are/our-definition-of-financialinclusion. Accessed on October 1, 2018. 
Chanchani, Radha; and Fagun Rajkotia (2012). A Study of the Auto-Rickshaw Sector in Bangalore City - Suggestions for Improved Governance. Bangalore, India: Indian Institute of Science, Centre for Infrastructure, Sustainable Transport and Urban Planning. cistup.iisc.ernet.in/pdf/newsandevents/Autorickshaws-Blore_FinalReport_Dec12_Cistup.pdf.

Accessed on October 31, 2018.

Chen, Le; Alan Mislove; and Christo Wilson (2015). Peeking Beneath the Hood of Uber. IMC'15: Proceedings of the ACM Internet Measurement Conference, Tokyo, Japan, October 28-30, 2015. New York: ACM Press, pp. 495-508.

Chu, Albert (2017). Mobile Technology and Financial Inclusion. In David Lee; Kuo Chen; and Robert H Deng (eds): Handbook of Blockchain, Digital Finance, and Inclusion. Elsevier. vol. 1. Chapter 6. pp. 131-144.

Civitas Consultants Private Limited for City Connect Foundation Chennai (2010). Study on the Auto-rickshaw sector in Chennai. http://chennaicityconnect.com/wpcontent/uploads/2011/03/AutoStudy-Chennai.pdf. Accessed on October 10, 2018.

Collins, Daryl; Jonathan Murdoch; Stuart Rutherford; and Orlanda Ruthven (2009). Portfolios of the Poor: How the World's Poor Live On \$2 a Day. Princeton: Princeton University Press.

Donovan, Kevin (2018). "Financial Inclusion Means Your Money Isn't with You”: Conflicts over Social Grants and Financial Services in Africa. In Bill Maurer; Smoki Musaraj; and Ivan Small (eds): Money at the Margins: Global Perspectives on Technology, Financial Inclusion, and Design. New York: Berghahn Books, pp. 155-78.

Donovan, Kevin (2012). Mobile Money for Financial Inclusion. In Tim Kelly and Michael Minges (eds): Information and Communication for Development 2012. Washington DC: World Bank, pp. 61-73.

Economic Times (2018). Ola Launches 'Auto Unnati' for Auto Driver Partners. https://auto.economictimes.indiatimes.com/news/industry/ola-launches-auto-unnati-for-autodriver-partners/62932412. Accessed on November 1, 2018.

Felsteiner, Alek (2011). Working the crowd: employment and labour law in the crowdsourcing industry. Berkeley Journal of Employment and Labour Law, vol. 32. no. 1, pp. 143-204.

Ferreira, Jennifer; Mark Perry; and Sriram Subramanian (2015). Spending time with money: From shared values to social connectivity. CSCW'15: Proceedings of the $18^{\text {th }} A C M$ Conference on Computer-Supported Cooperative Work \& Social Computing, Vancouver, Canada, March 14-18, 2015. New York: ACM Press, pp. 1222-1234.

Ferreira, Jennifer; and Mark Perry (2014). Building an alternative social currency: Dematerialising and rematerialising digital money across media. HCIK'14: Proceedings of HCI Korea, Seoul, Korea, December 10-12, 2014. New York: ACM Press, pp. 122-131.

Freund, Andreas (2017). Automated, Decentralised Trust: A Path to Financial Inclusion. In David Lee; Kuo Chen; and Robert H Deng (eds): Handbook of Blockchain, Digital Finance, and Inclusion. Elsevier. vol. 1. Chapter 20. pp. 431-450.

Gates Foundation (2012). Financial Services for the Poor: Strategy Overview. Seattle: Bill and Melinda Gates Foundation. https://docs.gatesfoundation.org/Documents/fsp-strategyoverview.pdf. Accessed on November 1, 2018.

Gaver, William (1991). Technology Affordances. CHI'91: Proceedings of the International SIGCHI Conference on Human Factors in Computing Systems, New Orleans, USA, April 27-May 2, 1991. New York: ACM Press, pp. 79-84.

Gaver, William (1992). The Affordances of Media Spaces for Collaboration. CSCW'92: Proceedings of the Conference on Computer-Supported Cooperative Work, Toronto, Canada, October 31-November 4, 1992. New York: ACM Press, vol. 1, no. 4, pp. 17-24. 
Ghosh, Ishita; Jay Chen; Joy Ming; and Azza Abouzied (2015). The Persistence of Paper: A case study in microfinance from Ghana. ICTD'15: Proceedings of the Seventh International Conference on Information and Communication Technologies and Development, Singapore, May 15-18, 2015. Article 13. New York: ACM Press, p. 13.

Ghosh, Saibal (2017). Financial inclusion, biometric identification and mobile: unlocking the JAM trinity. International Journal of Development Issues, vol. 16. no. 2, pp. 190-213.

Gillespie, Tarleton (2010). The Politics of 'Platforms'. New Media \& Society, vol. 12. no. 3, pp. 347-364.

Glöss, Mareike; Moira McGregor; and Barry Brown (2016). Designing for Labour: Uber and the On-Demand Mobile Workforce. CHI'16: Proceedings of the International SIGCHI Conference on Human Factors in Computing Systems, San Jose, USA, May 7-12, 2016. New York: ACM Press, pp. 1632-43.

Gupta, Neha; David Martin; Benjamin Hanrahan; and Jacki O'Neill (2014). Turk-life in India. GROUP'14: Proceedings of the 18th International Conference on Supporting Group Work, Sanibel Island, USA, November 9-12, 2014. New York: ACM Press, pp. 1-11.

Gusto, Anatoly Jing; and Emily Roque (2018). Delivering Cash Grants to Indigenous Peoples through Cash Cards versus Over-the-Counter Modalities: The Case of the 4Ps Conditional Cash Transfer Program in Palawan, Philippines. In Bill Maurer; Smoki Musaraj; and Ivan Small (eds): Money at the Margins: Global Perspectives on Technology, Financial Inclusion, and Design. New York: Berghahn Books, pp. 247-65.

Halloluwa, Tillina; Pradeepa Bandara; Hakim Usoof; and Dhaval Vyas (2018). Value for Money: Co-designing with underbanked women from rural Sri Lanka. OzCHI'18: Proceedings of the $30^{\text {th }}$ Australian Conference on Human-Computer Interaction, Melbourne, Australia, December 5-7, 2018. New York: ACM Press, pp. 63-73.

Harmon, Ellie; and Max Six Silberman (2017). Rating Working Conditions in Digital Labour Platforms. Computer Supported Cooperative Work (CSCW), vol. 27, no. 3-6, pp. 1275-1324.

Hughes, Nick; and Susie Lonie (2007). M-PESA: Mobile Money for the "Unbanked" Turning Cellphones into 24-Hour Tellers in Kenya. Innovations: Technology, Governance, Globalization, vol. 2. no. 1-2, pp. 63-81.

Ikkala, Tapio; and Airi Lampinen (2015). Monetizing network hospitality: Hospitality and sociality in the context of Airbnb. CSCW'15: Proceedings of Computer-Supported Cooperative Work \& Social Computing, Vancouver, Canada, March 14-18, 2015. New York: ACM Press, pp. 10331044.

Irani, Lilly (2015). Difference and Dependence among Digital Workers: The Case of Amazon Mechanical Turk. South Atlantic Quarterly, vol. 114. no. 1, pp. 225-34.

Isaac, Emily (2014). Disruptive Innovation: Risk-Shifting and Precarity in the Age of Uber. Roundtable on the International Economy BRIE Working Paper 2014-7, December 7, 2014. brie.berkeley.edu. Accessed on October 21, 2018.

Jaitley, Arun (2017). Demonetisation - A Look Back at the last Two Months. Yojana. New Delhi: Government of India. vol. 61, pp. 7-9.

Jhaver, Shagun; Yoni Karpfen; and Judd Antin (2018). Algorithmic Anxiety and Coping Strategies of Airbnb Hosts. CHI'18: Proceedings of the International SIGCHI Conference on Human Factors in Computing Systems, Montreal, Canada, April 21-26, 2018. Article 421. New York: ACM Press. Kaptelinin, Victor; and Bonnie Nardi (2012). Affordances in HCI: Toward a Mediated Action Perspective. CHI'12: Proceedings of the International SIGCHI Conference on Human Factors in Computing Systems, Austin, USA, May 5-10, 2012. New York: ACM Press, pp. 967-976. 
Kaye, Joseph Jofish; Mary McCuistion; Rebecca Gulotta; and David A. Shamma (2014). Money Talks: Tracking Personal Finances. CHI'14: Proceedings of the International SIGCHI Conference on Human Factors in Computing Systems, Toronto, Canada, April 26-May 1, 2014. New York: ACM Press, pp. 521-530.

Kendall, Jake; Bill Maurer; Phillip Machoka; and Clara Veniard (2012). An Emerging Platform: From Mobile Money Transfer to Mobile Money Ecosystem. Innovations: Technology, Governance, Globalization, vol. 6. no. 4, pp. 49-64.

Kiiti, Ndunge; and Jane Wanza Mutinda (2018). The Use of Mobile-Money Technology among Vulnerable Populations in Kenya: Opportunities and Challenges for Poverty Reduction. In Bill Maurer; Smoki Musaraj; and Ivan Small (eds): Money at the Margins: Global Perspectives on Technology, Financial Inclusion, and Design. New York: Berghahn Books, pp. 66-86.

Koh, Francis; Kok Fai Phoon; and Cao Duy Ha (2017). Digital Financial Inclusion in South East Asia. In David Lee; Kuo Chen; and Robert H Deng (eds): Handbook of Blockchain, Digital Finance, and Inclusion. Elsevier. vol. 2. Chapter 15. pp. 387-403.

Kumar, Deepti; David Martin; and Jacki O'Neill (2011). The Times They Are A-Changin': Mobile Payments in India. CHI'11: Proceedings of the International SIGCHI Conference on Human Factors in Computing Systems, Vancouver, Canada, May 7-12, 2011. New York: ACM Press, pp. 1413-1422.

Lee, Min Kyung; Daniel Kusbit; Evan Metsky; and Laura Dabbish (2015). Working with Machines: The Impact of Algorithmic and Data-Driven Management on Human Workers. CHI'15: Proceedings of the International SIGCHI Conference on Human Factors in Computing Systems, Seoul, Korea, April 18-23, 2015. New York: ACM Press, pp. 1603-1612.

Lewis, Makayla; and Mark Perry (2019). Follow the Money: Managing Personal Finance Digitally. CHI'19: Proceedings of the International SIGCHI Conference on Human Factors in Computing Systems, Glasgow, UK, May 4-9, 2019. New York: ACM Press.

Mainwaring, Scott; Wendy March; and Bill Maurer (2008). From meiwaku to tokushita!: Lessons for digital money design from Japan. CHI'08: Proceedings of the SIGCHI Conference on Human Factors in Computing Systems, Florence, Italy, April 5-10, 2008. New York: ACM Press, pp. 2124.

Martin, David; Jacki O’Neill; Neha Gupta; and Benjamin Hanrahan (2016). Turking in a global labour market. Computer Supported Cooperative Work (CSCW), vol. 25. no. 1, pp. 39-77.

Mas, Ignacio; and Daniel Radcliffe (2011). Mobile Payments Go Viral: M-PESA in Kenya. Journal of Financial Transformation, vol. 1, no. 32, pp. 169-82.

Mas, Ignacio; and Olga Morawczynski (2009). Designing Mobile Money Services: Lessons from M-PESA. Innovations: Technology, Governance, Globalization, vol. 4. no. 2, pp. 77-91.

Maurer, Bill; Musaraj, Smoki; and Ivan Small (eds). (2018). Money at the Margins: Global Perspectives on Technology, Financial Inclusion, and Design. New York: Berghahn Books.

Medhi, Indrani; Aishwarya Ratan; and Kentaro Toyama (2009). Mobile Banking Adoption and Usage by Low-Literate, Low-Income Users in the Developing World. Bangalore, India: Microsoft Research India. $\quad$ http://www.gsmworld.com/mobilefordevelopment/wpcontent/uploads/2012/06/hcii2009 medhi ratan toyama_d_26.pdf. Accessed on October 30, 2018. Mehra, Apurv; Srihari Muralidhar; Sambhav Satija; Anupama Dhareshwar; and Jacki O'Neill (2018). Prayana: Intermediated Financial Management in Resource-Constrained Settings. CHI'18: Proceedings of the SIGCHI Conference on Human Factors in Computing Systems, Montreal, Canada, April 21-26, 2018. New York: ACM Press, p. 389. 
Morawczynski, Olga; David Hutchful; Edward Cutrell; and Nimmi Rangaswamy (2010). The Bank Account is not Enough: Examining Strategies for Financial Inclusion in India. ICTD'10: Proceedings of the Fourth IEEE International Conference on Information and Communication Technologies and Development, London, UK, December 13-16, 2010. New York: ACM Press, p. 24.

Morozov, Evgeny (2014). To Save Everything Click Here: Technology, solutionism and the urge to fix problems that don't exist. New York: Public Affairs.

Mukherjee, Arpita; and Tanu Goyal (2017). Less-Cash Economy: India Vis-à-vis the World. Yojana. New Delhi: Government of India. vol. 61, February 2017, pp. 28-33.

Muralidhar, Srihari Hulikal; Claus Bossen; Apurv Mehra; and Jacki O’Neill (2018). Digitizing Monetary Ecologies: Intended and Unintended Consequences of Introducing a Financial Management App in a Low-Resource Setting. CSCW'18: Proceedings of the ACM on HumanComputer Interaction, vol. 2, November 2018, Article 72. New York: ACM Press.

Musaraj, Smoki; and Ivan Small (2018). Introduction: Money and Finance at the Margins. In Bill Maurer; Smoki Musaraj; and Ivan Small (eds): Money at the Margins: Global Perspectives on Technology, Financial Inclusion, and Design. New York: Berghahn Books, pp. 1-18.

Nandhi, Mani (2018). Effects of Mobile Banking on the Savings Practices of Low-Income Users the Indian Experience. In Bill Maurer; Smoki Musaraj; and Ivan Small (eds): Money at the Margins: Global Perspectives on Technology, Financial Inclusion, and Design. New York: Berghahn Books, pp. 266-286.

Natarajan, Subhashree; and Sheik Abdullah (2014). Social Organizations: Decongesting the Meddled Economies of Auto-Rickshaw Drivers in India. World Applied Sciences Journal. vol. 30. no. 7 , pp. 831-837.

Nelms, Taylor; and Stephen Rea (2017). Mobile Money: The First Decade. Institute for Money, Technology and Financial Inclusion, University of California, Irvine, USA.

Norman, Donald (1988). The Design of Everyday Things. New York: Basic Books.

O'Neill, Jacki; Anupama Dhareshwar; and Srihari Muralidhar (2017). Working Digital Money into a Cash Economy: The Collaborate Work of Loan Payment. Computer Supported Cooperative Work (CSCW), vol. 26, no. 4-6, December 2017, pp. 733-768.

Pal, Joyojeet; Priyank Chandra; Vaishnav Kameswaran; Aakanksha Parameshwar; Sneha Joshi; and Aditya Johri (2018). Digital Payment and its Discontents: Street Shops and the Indian Government's Push for Cashless Transactions. CHI'18: Proceedings of the International SIGCHI Conference on Human Factors in Computing Systems, Montreal, Canada, April 21-26, 2018. New York: ACM Press, p. 229.

Panjwani, Saurabh; Mohona Ghosh; Ponnurangam Kumaraguru; and Soumya Vardhan Singh (2013). The paper slip should be there!: Perceptions of transaction receipts in branchless banking. MobileHCI'13 Proceedings of the $15^{\text {th }}$ International Conference on human-computer interaction with mobile devices and services, Munich, Germany, August 27-30, 2013. New York: ACM Press, pp. 328-331.

Papaioannou, Theo. (2011). Technological Innovation, Global Justice and Politics of Development. Progress in Development Studies. vol. 11, no. 4, July 2011, pp. 321-338.

Parikh, Tapan; Paul Javid; Sasikumar; and Kaushik Ghosh (2006). Mobile Phones and Paper Documents: Evaluating a New Approach for capturing Microfinance Data in Rural India. CHI'06: Proceedings of the International SIGCHI Conference on Human Factors in Computing Systems, Montreal, Canada, April 22-27, 2006. New York: ACM Press, pp. 551-560.

Perry, Mark; and Jennifer Ferreira (2018). Moneywork: Practices and Use of Social Interaction around Digital and Analog Money. ACM Transactions on Human-Computer Interaction (TOCHI). New York: ACM Press. vol. 24. no. 6 (January 2018), pp. 41:1-41:32. 
Pritchard, Gary; John Vines; and Patrick Olivier (2015). Your Money's No Good Here: The Elimination of Cash Payment on London Buses. CHI'15: Proceedings of the International SIGCHI Conference on Human Factors in Computing Systems, Seoul, Korea, April 18-23, 2015. New York: ACM Press, pp. 907-916.

Rajan, Raghuram. (2008). Report of the Committee on Financial Sector Reforms. New Delhi: Planning Commission, Government of India.

Randall, David; Richard Harper; and Mark Rouncefield (2007). Fieldwork for Design: Theory and Practice. New York: Springer.

Rangarajan, Chakravarthi. (2006). Report of the Committee on Financial Inclusion. New Delhi: Ministry of Finance, Government of India.

Ratan, Aishwarya Lakshmi; Kentaro Toyama; Sunandan Chakraborty; Keng Sing Ooi; Mike Koenig; Pushkar Chitnis; and Matthew Phiong (2010). Managing Microfinance with Paper, Pen and Digital Slate. ICTD'10: Proceedings of the Fourth ACM/IEEE International Conference on Information and Communication Technologies and Development, London, UK, December 13-16, 2010. Article 37. New York: ACM Press, p. 13.

Raval, Noopur; and Paul Dourish (2016). Standing Out from the Crowd: Emotional Labour, Body Labour, and Temporal Labour in Ridesharing. CSCW'16: Proceedings of the 19 $9^{\text {th }}$ ACM Conference on Computer-Supported Cooperative Work \& Social Computing, San Francisco, USA, February 27-March 2, 2016. New York: ACM Press, pp. 97-107.

Rosenblat, Alex; and Luke Stark (2016). Algorithmic Labour and Information Asymmetries: A Case Study of Uber's Drivers. International Journal of Communication. vol. 10, pp. 3758-3784.

Roy, Ananya (2010). Poverty Capital: Microfinance and the Making of Development. New York: Routledge.

Rutherford, Stuart (2009). The Poor and Their Money: Microfinance from a Twenty-First Century Consumer's Perspective. New Delhi: Oxford University Press.

Sachs, Jeffrey (2005). The End of Poverty: Economic Possibilities of Our Time. New York: Penguin Press.

Sahoo, Pravakar; and Amogh Arora (2017). From a Cashless Economy to Less-Cash Economy. Yojana. New Delhi: Government of India, vol. 61, February 2017, pp. 11-15.

Saurabh, Sameera (2017). Achieving a Cashless Rural Economy. Yojana. New Delhi: Government of India, vol. 61, February 2017, pp. 34-37.

Sellen, Abigail; and Richard Harper (1997). Paper as an Analytic Resource for the Design of New Technologies. CHI'97: Proceedings of the International SIGCHI Conference on Human Factors in Computing Systems, Atlanta, USA, March 22-27, 1997. New York: ACM Press, pp. 319-326.

Sen, Amartya (1999). Development as Freedom. New Delhi: Oxford University Press.

Shapiro, Aaron (2017). Between autonomy and control: Strategies of arbitrage in the "on-demand" economy. New Media \& Society, vol. 20. no. 8, pp. 2954-2971.

Silberman, Max Six; Lilly Irani; and Joel Ross (2010). Ethics and Tactics of Professional Crowdwork. ACM XRDS 2010, vol. 17. no 2, pp. 39-43.

Silberman, Max Six (2010). What's fair? Rational action and its residuals in an electronic market. Unpublished manuscript. http://scribd.com/doc/86592724/Whats-Fair. Accessed on November 1, 2018.

Singh, Charan; and Shivakumara Reddy (2018). Facilitating Financial Inclusion. Yojana. New Delhi: Government of India, vol. 62, January 2018, pp. 24-33.

Sun, Tao (2017). Balancing Innovation and Risks in Digital Financial Inclusion - Experiences of ANT Financial Services Group. In David Lee; Kuo Chen; and Robert H Deng (eds): Handbook of Blockchain, Digital Finance, and Inclusion. Elsevier. Vol. 2. Chapter 2, pp. 37-43. 
Survey, Economic (2015). 'Wiping every tear from every eye': the JAM Number Trinity Solution. New Delhi. Government of India. Chapter 03, pp. 52-66.

Survey, Economic (2016). Spreading JAM Across India's Economy. New Delhi. Government of India. Chapter 03, pp. 50-68.

Taylor, Erin; and Heather Horst. (2018). A Living Fence: Financial Inclusion and Exclusion on the Haiti-Dominican Republic Border. In Bill Maurer, Smoki Musaraj, and Ivan Small (eds): Money at the Margins: Global Perspectives on Technology, Financial Inclusion, and Design. New York: Berghahn Books, pp. 23-43.

Toyama, Kentaro (2015). Geek Heresy: Rescuing Social Change from the cult of Technology. New York: Public Affairs.

Vines, John; Mark Blythe; Paul Dunphy; and Andrew Monk (2011). Eighty-somethings: Banking for the older old. HCI2011: Proceedings of the 25th BCS Conference on Human-Computer Interaction, Newcastle Upon Tyne, UK, July 4-8, 2011. British Computer Society, pp. 64-73.

Vines, John; Paul Dunphy; and Andrew Monk (2014). Pay or Delay: the role of technology when managing a low income. CHI'14: Proceedings of the 32 ${ }^{\text {nd }}$ Annual ACM Conference on Human Factors in Computing Systems, Toronto, Canada, April 26-May 1, 2016. New York: ACM Press, pp. 501-510.

Vyas, Dhaval; Stephen Snow; Paul Roe; and Margot Brereton (2016). Social Organisation of household finance: Understanding artful financial systems in the home. CSCW'16: Proceedings of the $19^{\text {th }}$ ACM Conference on Computer-Supported Cooperative Work \& Social Computing, San Francisco, USA, February 27-March 2, 2016. New York: ACM Press, pp. 1777-1789.

Yu, Sarah; and Samia Ibtasam (2018). A Qualitative Exploration of Mobile Money in Ghana. COMPASS'18: Proceedings of ACM Conference on Computing and Sustainable Societies, San Jose, USA, June 20-22, 2018. New York: ACM Press, p. 21.

Zelizer, Viviana Rotman (1995). The Social Meaning of Money. Princeton: Princeton University Press. 